\section{Cannabis e Saúde Mental - Uma Revisão sobre a Droga de Abuso e o Medicamento}

Antônio Waldo Zuardi, José Alexandre de Souza Crippa, Francisco Silveira Guimarães et al. Ribeirão Preto: FUNPEC-Editora; 2008.

O livro Cannabis e Saúde Mental foi escrito por autores pósgraduados na área de Psiquiatria, Neurologia e Farmacologia, especialistas na temática vinculada às substâncias psicoativas e à dependência química, sendo alguns deles renomados investigadores e professores de universidades, o que corrobora a seriedade com que o assunto é abordado. Como o próprio subtítulo aponta, eles revisam desde aspectos históricos do uso da maconha até as mais recentes descobertas científicas relacionadas a ela. Perpassam por temas costumeiramente polêmicos, como o uso medicamentoso dessa droga, porém sem emitir opiniões pessoais, fazendo um relato não preconceituoso e metodologicamente crítico sobre as evidências atualmente disponíveis.

O primeiro capítulo descreve os primórdios do uso da cannabis pelas civilizações asiáticas, enfatizando a busca por seus efeitos medicinais e no psiquismo, passando pela sua posterior difusão para o ocidente e o preocupante aumento do consumo com finalidade hedonística nas últimas décadas.

Em seguida, o leitor encontra um detalhado estudo da farmacologia da maconha, incluindo os tipos de canabinóides e outras substâncias contidas nessa droga. O tópico sobre a interação medicamentosa torna-se especialmente importante para médicos e psiquiatras que lidam com pacientes usuários. Da mesma forma, o conhecimento dos efeitos da cannabis sobre o sistema nervoso também tem extrema utilidade para os demais profissionais da saúde. Para explicar de forma mais didática o impacto da maconha sobre a noção do tempo, por exemplo, os autores citam Baudeleaire: "...a noite inteira era mensurável pela profusão dos meus pensamentos... Ainda que ela tenha me parecido longa, tive a impressão de que havia durado apenas alguns segundos". E explicam que esses efeitos variam de acordo com cada indivíduo, experiência prévia e setting no qual a droga é utilizada. Ressaltam também que a recente descoberta dos receptores canabinóides auxiliou a compreender o complexo papel dos endocanabinóides e da droga no organismo humano, facilitando o desenvolvimento de agonistas e antagonistas com fins terapêuticos.

Outros capítulos não menos relevantes destacam os efeitos neurofisiológicos e cognitivos da maconha. Além disso, são mencionadas as técnicas de neuroimagem estruturais e funcionais utilizadas para avaliar os usuários, clareando-se a existência dos inúmeros danos causados pelo uso crônico dessa droga. Danos esses que podem também repercutir diretamente na psicopatologia. Por isso, em seqüência, os autores tecem considerações, por meio da apresentação de estudos epidemiológicos, prospectivos e com populações de alto risco, sobre a associação do uso de maconha com alguns transtornos mentais, como os de ansiedade, humor e psicóticos, inclusive adentrando na antiga discussão sobre ela causar ou não esquizofrenia.

Um capítulo particularmente interessante é o que discorre sobre o canabidiol, substância também contida na mesma planta em grandes quantidades, mas pouco conhecida dos psiquiatras. Seus efeitos são atípicos (hipnótico, anticonvulsivante,

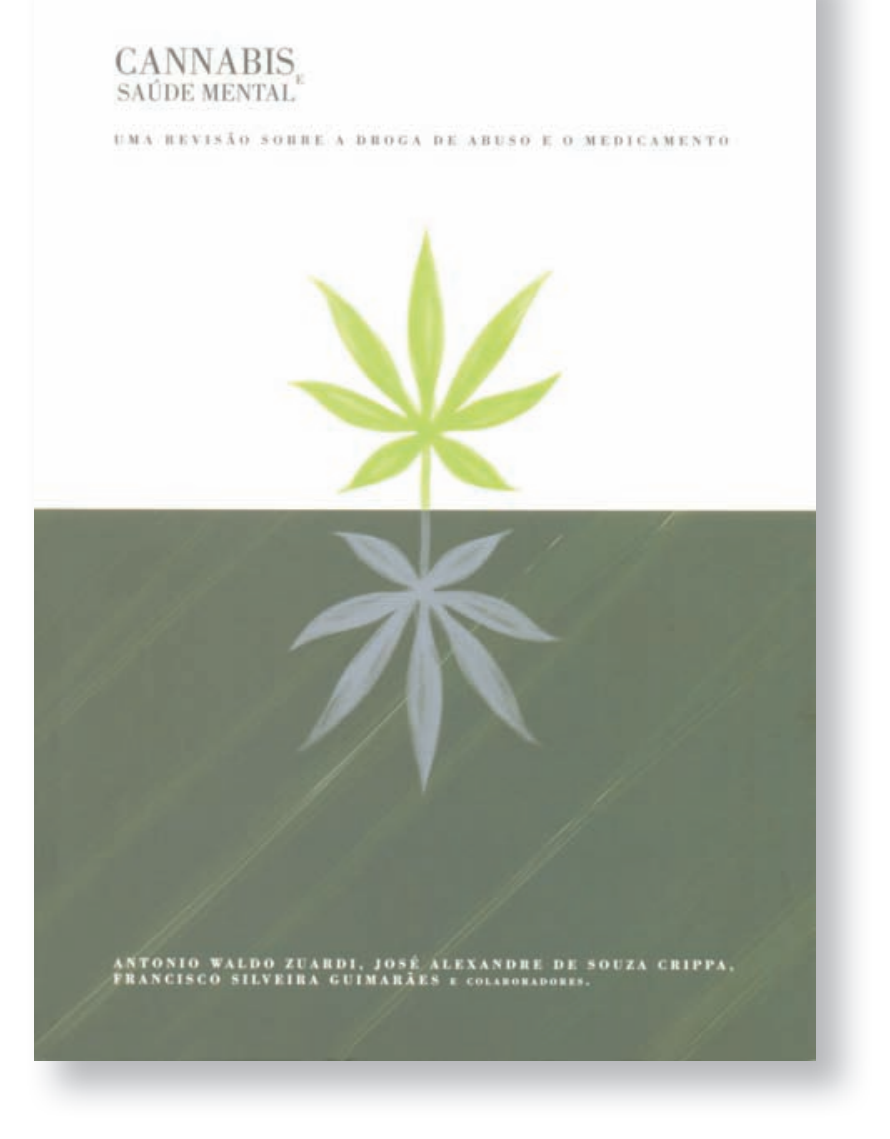

neuroprotetor) e diferenciados daqueles desencadeados pelo THC (tetrahidrocannabinol). Os autores ainda analisam as potenciais aplicações terapêuticas dessa substância nos transtornos ansiosos e psicóticos.

Finalmente, o livro enfoca, nos últimos capítulos, a questão do diagnóstico psiquiátrico e traz os avanços e perspectivas para o tratamento farmacológico do uso de cannabis, além de algumas psicoterapias utilizadas para dependentes químicos. Entretanto, não tem objetivo de contemplar as políticas preventivas ou de se aprofundar na descrição das estratégias de tratamento e outras técnicas psicoterápicas específicas para a abordagem dos pacientes usuários da maconha, algumas já bem descritas na literatura americana. Também não amplia a discussão da problemática familiar e de outras repercussões sociais e culturais do uso dessa droga no Brasil.

Mas isso não diminui o seu mérito. Há muito tempo era necessária uma publicação de alto nível para um tema tão controverso, muitas vezes exposto na mídia de forma incorreta. 0 conteúdo nele inserido certamente elucidará inúmeras dúvidas do público leigo e mesmo de profissionais da saúde. Apesar de ser um texto eminentemente técnico, propicia uma fácil e agradável leitura, trazendo contribuições originais sobre esse assunto à literatura brasileira.

Felix Kessler

Centro de Pesquisa em Álcool e Drogas, Universidade Federal do Rio Grande do Sul (UFRGS), Porto Alegre (RS), Brasi 